\title{
Long Term Care in Japan and Sweden: A Comparison of Target Population, Needs and Services Provided from 2000-2010
}

\section{Marten Lagergren ${ }^{1^{*}}$, Noriko Kurube ${ }^{2}$ and Yasuhiko Saito ${ }^{3}$}

${ }^{1}$ Stockholm Gerontology Research Center, Stockholm, Sweden

${ }^{2}$ Nihon Fukushi University, Aichi, Japan

${ }^{3}$ Nihon University, Tokyo, Japan

*Corresponding author: Marten Lagergren, Stockholm Gerontology Research Center, Gävlegatan 16, 11260 Stockholm, Sweden, Tel: +46-8-690 58 12; Fax: +46-8-6905954; E-mail: marten.lagergren@aldrecentrum.se

Rec date: Jul 19, 2016; Acc date: Aug 02, 2016; Pub date: Aug 04, 2016

Copyright: (C) 2016 Lagergren M, et al. This is an open-access article distributed under the terms of the Creative Commons Attribution License, which permits unrestricted use, distribution, and reproduction in any medium, provided the original author and source are credited.

\begin{abstract}
This study aims to show how provision of long term care services has been affected by changes in population, needs of long term care by age-group and gender and provided services by level of need in Japan and Sweden 2000-2010. Data in the Japanese case were taken from the NUJLSOA-study and from registrations in the Japanese Long Term Care Insurance- system from nine municipalities. Swedish data were taken from the nationally representative surveys of living conditions (SSLC) and from surveys relating provision to needs in eight municipalities. In both countries there has been a positive health development among the old citizens. The proportion receiving home-related long term care services in Japan increased by more than $50 \%$ during the first fiveyear period. In Sweden there was a much slower increase of long term care provisions. The 2005 Japanese long term care reform seems to have dampened provision increase, but it was still much more rapid in the period 2005-2010 than in Sweden.
\end{abstract}

Keywords: Long-term care; Comparison; Dependency; Old age; Service provision; Japan; Sweden

\section{Introduction}

Eldercare systems in Japan and Sweden are facing similar challenges. There is an increasing number of older adults in both countries as well as a continued public ambition to provide access to long term care (LTC) and services for those in need. These similarities and indeed the differences between the two countries make comparisons between the two eldercare systems interesting.

In 2000 Japan introduced a national long-term care insurance (LTCI) scheme covering all citizens aged 65 years and above. The purpose of the system is twofold-firstly to guarantee that older adults receive long-term care and services appropriate to their needs and secondly, to ensure fairness and national equity. A prominent aspect of the Japanese system is the very detailed formal system for certifying the care needs of elderly people. This system is standardized and uniform throughout the country $[1,2]$.

An application from an elderly person starts the certification process. The next step is a very thorough examination by an assessor using a standardized national questionnaire that covers various aspects of disability [3]. The data are entered into a computer model which in turn assigns a preliminary care level. Following revisions to the original categorization of care levels in 2006 there are now eight possible categories: "not eligible", two support levels and care levels graded from 1-5.

This computer generated decision is then reviewed by a nursing care needs certification board consisting of physicians, nurses and other experts in health and social care services. If necessary the board can reassign the care level taking into account factors that may not have been covered by the formal registration process. The assigned care level determines how much money can be used for LTC services. The final step consists of care management-that is planning and coordinating care services. In this step the elderly person and his/her family, together with a professional care manager, plans the actual content of the LTC services.

In Sweden a decentralized, tax-based system of LTC has been in place since the 1970s. The Social Service Act states that the municipality has an obligation to provide assistance if the person's needs cannot be met in any other way [4]. However, the legislation does not specify how LTC needs should be assessed so there is no formal standardized procedure as there is in Japan. Needs assessments are carried out by the municipalities and the methods and procedures used vary greatly. The needs assessment usually takes into account the individual's living situation including their home environment, available social support etc. In practice this results in large differences in service provision depending on whether the person is co-habiting or not. Care services are then allocated in terms of hours of services rather than as a monetary sum. However, in practice what is actually provided can differ considerably from what was granted. Studies have also shown wide variations not only between different municipalities in Sweden but also the decisions made by different needs' assessors [5].

The cost of providing LTC depends on the size of the target population, the LTC needs of each person in that population, the services provided given the level of need and the costs to provide these services. Thus the cost development can be broken down into changes in

- Population - age-group and gender

- Health - LTC needs according to age-group and gender

- Services - services provided per level of LTC need 


\section{- Costs - total costs of the services provided}

By breaking down LTC provision in this way it is possible to determine the relative importance of each of these factors on the level of LTC expenditure in Japan and Sweden. This article will focus on the first three components. The costs of LTC given the demographic changes, needs and the services provided will be described and analyzed in another article. The time period for the current study is 2000-2010. Different datasets will be used for the analyses-population data, data describing the prevalence of ill-health and dependency and data that links the services provided to the needs expressed in terms of ill-health or dependency.

There are very few studies that compare the LTC systems in different countries using micro data. Woittiez et al. compared LTC use in nine European countries using SHARE data (Survey of Health, Aging and Retirement in Europe) in an effort to estimate the coverage of informal and formal care according to needs [6]. Boyd et al. compared dependency levels among residents in long term care homes in four countries (Australia, New Zealand, Spain and UK) and concluded that functional dependency was high and comparable internationally [7]. Comparisons between Japanese and Swedish LTC systems have been made using micro data collected from assessments carried out in the Japanese LTC Insurance system and corresponding data from various studies in Sweden [8-11].

There are also other types of studies that are relevant in this context. Karlsson et al. conducted a comparative study concerning equity, efficiency and sustainability of LTC arrangements in Japan, Sweden and Germany [12]. In his study of the future of LTC in Japan Shimizutani described current developments within the LTC system with a special emphasis on the incentive mechanisms being used [13]. $\mathrm{He}$ also explored future projections of costs for LTC provision. Another future-oriented study of the Japanese LTC system was conducted by Mitchell et al. who investigated alternative cost projections and more efficient ways of organizing and financing LTC provision [14].

The aim of this article is to demonstrate how the provision of LTC services in Japan and Sweden has been affected by recent demographic changes in the old adult population, the LTC needs of this group and the provision of services in relation to these needs in the period 2000-2010 divided into the sub-periods 2000-2005 and 2005-2010. In order to be able to measure effects of the 2005 Japanese LTC reform results are also given for the year 2006 in the Japanese case. Since needs are not measured in the same way in the two countries it is not possible to make direct comparisons between them. Instead the primary purpose of the article is to analyze the developments within each country using the same methodology.

\section{Material and Methods}

\section{Data sources-population}

In the analyses presented below official population data provided by Statistics Japan and Statistics Sweden were used.

\section{Data sources-needs}

The next step in the analysis involved determining the changing need for LTC services given the demographic development. The main factor determining need for LTC services is ill-health or disability. This can be measured in different ways including: dependency in activities of daily living (ADL), cognitive disability, mobility impairments etc. For the Japanese study this information has been taken from the nationally representative survey "Nihon University, Japanese Longitudinal Study of Aging (NUJLSOA)" [15].

Several measurements of ill-health are used in NUJLSOA-including questions concerning an individual's ability to perform daily activities such as taking a bath or shower, dressing, eating, going to bathroom and using the toilet, standing up from a bed or chair. For each of these activities it is noted whether the individual finds the task difficult or not and, if any difficulty is experienced, whether the individual finds it somewhat difficult, very difficult or is unable to perform the task.

In the present study an individual has been categorized as being dependent for an activity if s/he said that they found a task "very difficult" or were "unable" to do it. The number of dependencies was then added up for each participant. In addition it was noted whether the individual is able to walk outdoors (Question: Do you find it difficult going outside (leaving the house) due to your health or physical state?) Using all this information the individual's level of dependency was defined according to the following criteria:

- No ADL-dependencies and able to walk outdoors

- No ADL-dependencies but unable to walk outdoors

- 1-3 ADL-dependencies

- 4-5 ADL-dependencies

When presenting the results in this paper this categorization has been simplified to just two categories: "Independent or only partially dependent" and "Dependent" which is comprised of the three higher degrees of dependency.

Five waves of the NUJLSOA have been used for the analyses: 1999 (4830 observations,), 2001 (4537 obs.), 2003 (4399 obs.), 2006 (3328 obs.) and 2009 (2508 obs.). It should be noted that NUJLSOA is a longitudinal study. Thus the same people can appear in more than one wave. The total number of people that participated in the study was 6201. Since new participants were not recruited to the study after 2003 the number of younger participants subsequently decreased. Thus the 2006 wave only contained people aged 68 years and above and the 2009 wave was comprised only of individuals aged 70 years and over. People living in institutions were not included in the first wave but those who subsequently moved into institutions were interviewed by proxy in the follow-up surveys whenever possible.

Prevalence rates for the different levels of dependency were calculated by ten-year age groups (65-74, 75-84 and 85+) and gender for each wave. Then weighted linear regression over time was carried out for each ten-year age group and gender and for each level of dependency and in this way prevalence rates for the years 2000, 2005, 2006 and 2010 were calculated.

The corresponding Swedish data was taken from the Swedish surveys of living conditions (SSLC). These surveys have been conducted every two years since 1975 using essentially the same methodology and survey questionnaire. The SSLC contain several different indicators of ill-health and disability all of which are selfreported: ADL- and IADL-dependency, mobility impairments, activity limitations due to chronic disease, and self-reported general health. In the analyses presented below an index of ill-health, the so-called Statistics Sweden (SCB) health index, has been used. This index is constructed by combining information on self-reported health, global activity limitations (GALI), mobility impairments and the occurrence of chronic disease. There are four levels: no ill-health, mild ill-health, 
moderate ill-health and severe ill-health. In this paper the results are presented according to the categories "No to moderate ill-health" and "Severe ill-health".

The 2000/2001-SSLC survey is used to represent the year 2000, the 2004/2005-SSLC survey to represent the year 2005 and the 2010/2011SSLC survey to represent the year 2010. The number of observations of individuals aged 65 years and above was 2176, 2192 and 5065 respectively.

\section{Data sources-services provided}

The data used for relating services to needs in Japan was taken from registrations in the Japanese LTCI system in nine municipalities of varying sizes covering the period 1999-2012. For each municipality two datasets were obtained. The first dataset from each municipality contains for each assessed individual the result of the assessments of different kinds of functional limitations that were registered during the assessment procedure. These datasets have been divided according to assessment date into four 18 month periods: Oct 1999 (or the earliest time)-March 2001; Oct 2004-March 2006; April 2006-Sept 2007 and Oct 2009-March 2011. The choice of periods was made to illustrate the effects of the 2006 LTCI reform in Japan. Several assessments on the same individual may have been carried out during one time period. In this case only the first observation in each period was retained.

The other dataset from each municipality contains data regarding the kind of LTC services that were allocated-home-based care services or institutional care services. These data are registered on a monthly basis so there could be multiple observations for each person. As a result of the changes that followed the LTCI reform in March 2006 the set of registered variables differs depending on whether the registration was made before or after the reform took place. For each municipality and each 18 month period the first and the second dataset (for the corresponding half-period before and after the reform respectively) were merged. In this merged dataset there might be several observations of service provision for the same individual. To ensure that the services provided related to the relevant assessment, observations where services were allocated before the assessment date were deleted. Then for each person the observation with the earliest date of service provision was chosen. Finally the nine merged municipality datasets were added together for each time period. The total number of observations of individual people in these datasets was 13329 in the first period, 20977 in the second, 25014 in the third and 22378 in the fourth. The increasing numbers reflect the increase in the number of LTC recipients in Japan during the study period.

The LTCI assessment datasets contain a number of variables describing various forms of disability that are relevant for deciding on LTC provision. Of the many variables available those eventually chosen were associated with ADL and to limitations in mobility. The choice of variables was determined by the availability of corresponding disability variables in NUJLSOA.

The data used for services provided in relation to need in Sweden were taken from surveys performed in the years 2002 and 2007 in order to provide a basis for the Swedish municipality tax equalization system. These surveys involved eight municipalities from different parts of Sweden and included everyone of 65 years and over who received LTC-services-a total of 5326 in the first survey and 5111 in the second.
The surveys recorded the LTC services provided (hours of home help, institutional care) and different variables related to need (age, gender, ADL-dependency, mobility limitations, cognitive disability).

\section{Calculation method}

The first step in the analysis was to use the population and needs data (NUJLSOA and SSLC) to estimate the total number of older adults in Japan and Sweden according to their level of dependency/illhealth, gender and age-group (three age-groups were used: 65-74 years, 75-84 years and 85 years and above) by the years 2000, 2005, 2006 and 2010. These estimates were of course subject to estimation errors.

The next step in the analysis was to calculate the number of persons in the involved municipalities that received LTC services (home-based and institutional care) by gender, age-group and level of dependency/ ill-health using the municipal LTC services data in the respective countries each year. An estimate was made of the total number of old persons in the municipalities by gender, age-group and level of dependency/ill-health assuming the same distribution of dependency/ ill-health in the municipalities as in the whole country according to the previous step. In this way the proportion of older adults in the municipalities receiving LTC services could be calculated by type of LTC services, gender, age-group and level of dependency/ill-health by comparing the numbers receiving LTC services and the total number of old persons. Summarizing this figure to type of LTC services, gender and age-group a calibration was made by proportional adjusting to the proportions of people in total Japan and Sweden respectively receiving LTC services in the same year by type of LTC services, gender and agegroup. Finally the total number of persons receiving LTC-services by type of LTC, gender, age-group, and level of dependency/ill-health in the respective countries was calculated by multiplying the calibrated proportions with the total number of persons in the country by gender and age-group.

\section{Results}

\section{Population}

Table 1 shows the demographic changes in the Japanese population aged 65 years and above, by age group.

\begin{tabular}{|l|l|l|l|l|}
\hline & $\mathbf{6 5 - 7 4}$ years & $\mathbf{7 5 - 8 4}$ years & $\mathbf{8 5}$ years & All \\
\hline 2000 & 13.01 & 6.77 & 2.23 & 22.01 \\
\hline 2005 & 14.07 & 8.68 & 2.93 & 25.67 \\
\hline 2006 & 14.29 & 9.00 & 3.10 & 26.39 \\
\hline 2010 & 15.17 & 10.28 & 3.79 & 29.25 \\
\hline
\end{tabular}

Table 1: Number of people in the population (in millions) by agegroup in Japan.

A rapid increase can be observed in the number of people in all agegroups but the increase was most rapid in the oldest age-group with an increase of more than $70 \%$ in the ten year study period, which amounts to $5.4 \%$ a year in the period $2000-2010$. This has of course had a big impact on the demand for LTC as will be shown later in the article. The total population of those aged 65 and over increased by $33 \%$, corresponding to a yearly increase of $2.9 \%$. 
Page 4 of 8

\begin{tabular}{|l|l|l|l|l|}
\hline & $\mathbf{6 5 - 7 4}$ years & $\mathbf{7 5 - 8 4}$ years & $\mathbf{8 5}$ years & All age groups \\
\hline 2000 & 740.3 & 585.6 & 205.0 & 153.1 \\
\hline 2005 & 766.3 & 571.2 & 227.2 & 156.5 \\
\hline 2010 & 937.0 & 548.7 & 251.2 & 173.7 \\
\hline
\end{tabular}

Table 2: Number of people in the population (in thousands) in Sweden by age-group.

Also in Sweden a large increase can be observed in the number of the oldest old, but the most noticeable demographic change was the very rapid increase in the numbers in the youngest old age-groups. This had little impact on the LTC system in the period studied, but suggests that a large increase in the oldest age-groups can be expected in the 2020s and 2030s with knock-on effects in increasing LTC needs (Table 2).

\section{Changes in needs}

The need for LTC services increases with age but the demographic changes are not mirrored exactly with a direct increase in the demand for LTC services. The key factor in determining the need for LTC services is the prevalence of dependency or ill-health by age-group and gender. Using results from NUJLSOA Figure 1 show how the prevalence of dependency has changed in the Japanese population.

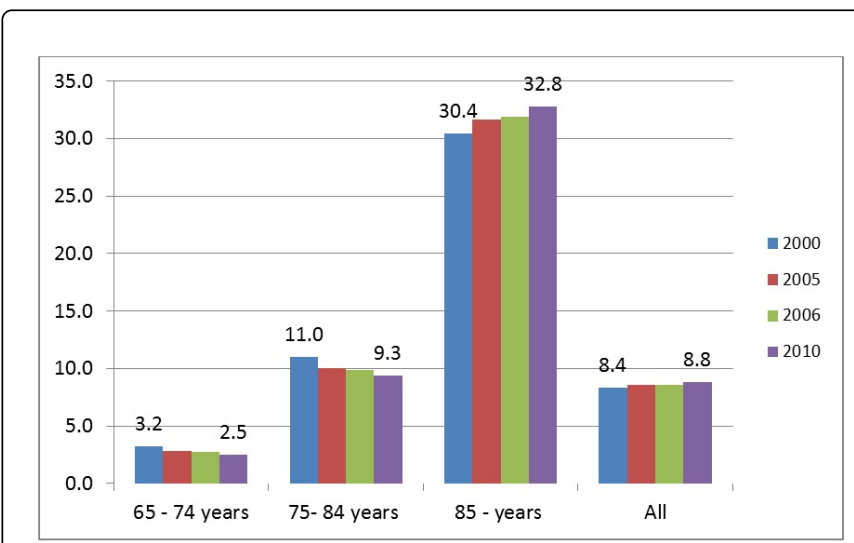

Figure 1: Proportion dependent by age-group, Japan, 2000-2010.

As expected the prevalence of dependent individuals increased with age. Dependency levels decreased in both the younger age-groups. The increase seen in the oldest age-group is the most important since this group contains the largest proportion of the LTC-recipients.

A limitation is that in the earlier waves of the study the data collected did not include people living in institutions. This was rectified to a limited extent in subsequent waves of the study. The result is that the dependency rates are under-estimated-especially in the oldest agegroups-but maybe to a somewhat lesser extent in later survey waves. However, there are indications (see below) that the ADL-dependency prevalence rates for the oldest age group are underestimated in the whole period. The corresponding developments in Sweden showing the prevalence of severe ill-health can be seen in Figure 2.

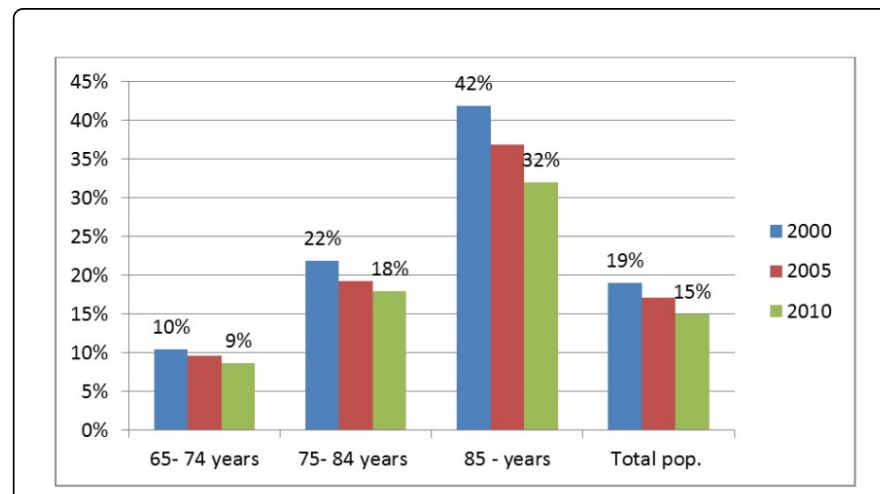

Figure 2: Proportion of people with severe ill-health by age-group, Sweden, 2000-2010.

In the Swedish case the prevalence decline affects all age-groups. This is part of a longer trend as measured by the SSLC since 1980. The most important difference to Japan is of course the development in the oldest age group.

\section{LTC services in relation to needs}

The next step in the analysis was to study the development of LTCservices in relation to needs. Many different types of services are available under the Japanese LTCI system and for the purposes of this study a division was made between home-based services provided to those still living at home-home help, home health care, home rehabilitation, day care etc. -and those in institutional care. The same division will be used to analyze the situation in Sweden. It should be noted that the composition of home-based LTC services differs between the two countries-in Japan there is a much higher proportion of people receiving day care than is the case in Sweden (cf [9]).

The proportion of people in the population receiving LTC in Japan by age and level of dependency is shown in Table 3 . To be noted is that the category "Independent or partially dependent" as defined in this study, i.e. no ADL-dependency and able to walk outside, does not mean that a person does not need any help in his/her daily life. Requiring help with household chores (IADL-dependency), is not measured in the assessment carried out under the Japanese LTCI system. The provision of LTC for the dependent persons is exaggerated, depending on the under-estimation of the proportion of ADLdependent persons in NUJLSOA, which was used as yard-stick for estimation of the prevalence of dependency. However, this should not affect comparisons over time.

Table 3 shows that dependent old adults in Japan were around eleven times as likely to receive home-based LTC services as independent persons or those who were only partially dependent. The proportion of independent or only partially dependent people living at home who received home-based LTC services almost doubled between 2000 and 2010-however, the level was still low at 5.7\%. Overall there was an increase of $69 \%$ in the proportion of older adults receiving home-based LTC services from $6.5 \%$ to $11 \%$.

As expected there was a very strong age gradient in the provision of LTC-services. A much higher proportion of those aged 85 years and above received LTC services than among the younger age-groups. Among the oldest old there has been a very rapid increase (64\%) in the 
Citation: Lagergren M, Kurube N, Saito Y (2016) Long Term Care in Japan and Sweden: A Comparison of Target Population, Needs and

Page 5 of 8

proportion of people receiving home-based services. The provision of home-based services to the younger age-groups has also increased but to a lesser degree - $27 \%$ and $43 \%$ respectively.

\begin{tabular}{|c|c|c|c|c|}
\hline Home-based & 2000 & 2005 & 2006 & 2010 \\
\hline \multicolumn{5}{|l|}{$65-74$ years } \\
\hline Independent or only partially dependent & $0.9 \%$ & $1.5 \%$ & $1.4 \%$ & $1.3 \%$ \\
\hline Dependent & $\begin{array}{l}39.4 \\
\%\end{array}$ & $54.8 \%$ & $61.7 \%$ & $63.9 \%$ \\
\hline All & $2.2 \%$ & $3.0 \%$ & $3.0 \%$ & $2.8 \%$ \\
\hline \multicolumn{5}{|l|}{ 75-84 years } \\
\hline Independent or only partially dependent & $5.2 \%$ & $8.2 \%$ & $7.6 \%$ & $7.6 \%$ \\
\hline Dependent & $\begin{array}{l}41.5 \\
\%\end{array}$ & $58.1 \%$ & $63.8 \%$ & $67.1 \%$ \\
\hline All & $9.2 \%$ & $13.2 \%$ & $13.1 \%$ & $13.2 \%$ \\
\hline \multicolumn{5}{|l|}{85 years } \\
\hline Independent or only partially dependent & $\begin{array}{l}13.1 \\
\%\end{array}$ & $23.1 \%$ & $20.5 \%$ & $24.2 \%$ \\
\hline Dependent & $\begin{array}{l}46.3 \\
\%\end{array}$ & $58.9 \%$ & $64.1 \%$ & $66.7 \%$ \\
\hline All & $\begin{array}{l}23.2 \\
\%\end{array}$ & $34.4 \%$ & $34.4 \%$ & $38.1 \%$ \\
\hline \multicolumn{5}{|l|}{ All age groups } \\
\hline Independent or only partially dependent & $3.1 \%$ & $5.6 \%$ & $5.1 \%$ & $5.7 \%$ \\
\hline Dependent & $\begin{array}{l}42.8 \\
\%\end{array}$ & $57.8 \%$ & $63.6 \%$ & $66.4 \%$ \\
\hline All & $6.5 \%$ & $10.0 \%$ & $10.2 \%$ & $11.0 \%$ \\
\hline \multicolumn{5}{|l|}{ Institutional care } \\
\hline \multicolumn{5}{|l|}{$65-74$ years } \\
\hline Independent or only partially dependent & $0.1 \%$ & $0.1 \%$ & $0.0 \%$ & $0.0 \%$ \\
\hline Dependent & $\begin{array}{l}15.2 \\
\%\end{array}$ & $16.0 \%$ & $17.2 \%$ & $14.5 \%$ \\
\hline All & $0.6 \%$ & $0.5 \%$ & $0.5 \%$ & $0.4 \%$ \\
\hline \multicolumn{5}{|l|}{$75-84$ years } \\
\hline Independent or only partially dependent & $0.7 \%$ & $0.4 \%$ & $0.3 \%$ & $0.2 \%$ \\
\hline Dependent & $\begin{array}{l}24.6 \\
\%\end{array}$ & $25.1 \%$ & $26.0 \%$ & $23.0 \%$ \\
\hline All & $3.3 \%$ & $2.9 \%$ & $2.8 \%$ & $2.3 \%$ \\
\hline \multicolumn{5}{|l|}{85 years } \\
\hline Independent or only partially dependent & $2.5 \%$ & $2.4 \%$ & $1.2 \%$ & $0.9 \%$ \\
\hline Dependent & $\begin{array}{l}38.5 \\
\%\end{array}$ & $38.8 \%$ & $41.2 \%$ & $33.7 \%$ \\
\hline All & $\begin{array}{l}13.4 \\
\%\end{array}$ & $13.9 \%$ & $13.9 \%$ & $11.7 \%$ \\
\hline All age groups & & & & \\
\hline
\end{tabular}

\begin{tabular}{|c|c|c|c|c|}
\hline Independent or only partially dependent & $0.5 \%$ & $0.4 \%$ & $0.2 \%$ & $0.2 \%$ \\
\hline Dependent & $\begin{array}{l}27.6 \\
\%\end{array}$ & $29.2 \%$ & $31.1 \%$ & $27.0 \%$ \\
\hline All & $2.7 \%$ & $2.9 \%$ & $2.9 \%$ & $2.5 \%$ \\
\hline Total LTC & 2000 & 2005 & 2006 & 2010 \\
\hline \multicolumn{5}{|l|}{$65-74$ years } \\
\hline Independent or only partially dependent & $1.0 \%$ & $1.6 \%$ & $1.4 \%$ & $1.3 \%$ \\
\hline Dependent & $\begin{array}{l}54.7 \\
\%\end{array}$ & $70.8 \%$ & $78.9 \%$ & $78.5 \%$ \\
\hline All & $2.7 \%$ & $3.5 \%$ & $3.5 \%$ & $3.2 \%$ \\
\hline \multicolumn{5}{|l|}{$75-84$ years } \\
\hline Independent or only partially dependent & $5.9 \%$ & $8.6 \%$ & $7.8 \%$ & $7.8 \%$ \\
\hline Dependent & $\begin{array}{l}66.1 \\
\%\end{array}$ & $83.1 \%$ & $89.7 \%$ & $90.1 \%$ \\
\hline All & $\begin{array}{l}12.5 \\
\%\end{array}$ & $16.1 \%$ & $16.0 \%$ & $15.5 \%$ \\
\hline \multicolumn{5}{|l|}{85 years } \\
\hline Independent or only partially dependent & $\begin{array}{l}15.6 \\
\%\end{array}$ & $25.5 \%$ & $21.7 \%$ & $25.1 \%$ \\
\hline Dependent & $\begin{array}{l}84.7 \\
\%\end{array}$ & $97.7 \%$ & $105.3 \%$ & $100.5 \%$ \\
\hline All & $\begin{array}{l}36.6 \\
\%\end{array}$ & $48.3 \%$ & $48.3 \%$ & $49.8 \%$ \\
\hline \multicolumn{5}{|l|}{ All age groups } \\
\hline Independent or only partially dependent & $3.6 \%$ & $6.0 \%$ & $5.4 \%$ & $5.8 \%$ \\
\hline Dependent & $\begin{array}{l}70.4 \\
\%\end{array}$ & $87.1 \%$ & $94.6 \%$ & $93.4 \%$ \\
\hline All & $9.2 \%$ & $12.9 \%$ & $13.0 \%$ & $13.6 \%$ \\
\hline
\end{tabular}

Note: Very high proportions for dependent persons result from some underestimation of dependency in NUJLSOA

Table 3: Proportion of people in the population receiving LTC by age and level of dependency, Japan, 2000-2010.

Of course, when considering institutional care there were big differences depending on people's level of dependency. In total the proportion of institutionalized people among all Japanese aged 65 years and above was small and only a very small proportion of those who were independent or only partially dependent received institutional care. However, more than a quarter of the dependent persons lived in LTC institutions. Over the study period the proportion of those living in institutions has been fairly stable in Japan with a small increase until 2006 followed by a decrease in 2010. The proportion of older people in each age group who lived in institutions decreased in all age-groups.

When considering all LTC services in Japan, large differences were found in the total provision of LTC according to the level of dependency, which was to be expected, and also between the different age-groups. There were some differences between the age-groups among those who were independent or only partially dependent but 
Citation: Lagergren M, Kurube N, Saito Y (2016) Long Term Care in Japan and Sweden: A Comparison of Target Population, Needs and Services Provided from 2000-2010. J Gerontol Geriatr Res 5: 331. doi:10.4172/2167-7182.1000331

Page 6 of 8

the differences were not so great among those who were ADLdependent. There was an increase in the proportion of people receiving LTC in all age-groups but this was more pronounced among the oldest old and among those independent or only partially dependent. In total the proportion of people aged 65 years and older receiving LTC services increased from 9 to almost $14 \%$. The corresponding results for Sweden are shown in Table 4.

\begin{tabular}{|c|c|c|c|}
\hline Home-Based LTC & 2000 & 2005 & 2010 \\
\hline \multicolumn{4}{|l|}{$65-74$ years } \\
\hline No to moderate ill-health & $2.2 \%$ & $1.8 \%$ & $2.3 \%$ \\
\hline Severe ill-health & $10.7 \%$ & $8.6 \%$ & $8.4 \%$ \\
\hline All & $3.1 \%$ & $2.5 \%$ & $2.4 \%$ \\
\hline \multicolumn{4}{|l|}{$75-84$ years } \\
\hline No to moderate ill-health & $10.3 \%$ & $9.7 \%$ & $9.5 \%$ \\
\hline Severe ill-health & $20.0 \%$ & $19.3 \%$ & $21.7 \%$ \\
\hline All & $12.5 \%$ & $11.1 \%$ & $11.8 \%$ \\
\hline \multicolumn{4}{|l|}{ 85- years } \\
\hline No to moderate ill-health & $5.7 \%$ & $5.6 \%$ & $5.4 \%$ \\
\hline Severe ill-health & $34.9 \%$ & $33.4 \%$ & $36.8 \%$ \\
\hline All & $34.4 \%$ & $31.5 \%$ & $32.4 \%$ \\
\hline \multicolumn{4}{|l|}{ All age groups } \\
\hline No to moderate ill-health & $8.3 \%$ & $7.6 \%$ & $7.5 \%$ \\
\hline Severe ill-health & $21.9 \%$ & $20.8 \%$ & $22.2 \%$ \\
\hline All & $10.9 \%$ & $9.9 \%$ & $9.7 \%$ \\
\hline \multicolumn{4}{|l|}{ Institutional care } \\
\hline \multicolumn{4}{|l|}{$65-74$ years } \\
\hline No to moderate ill-health & $0.3 \%$ & $0.3 \%$ & $0.3 \%$ \\
\hline Severe ill-health & $4.3 \%$ & $6.0 \%$ & $8.0 \%$ \\
\hline All & $0.7 \%$ & $0.9 \%$ & $0.9 \%$ \\
\hline \multicolumn{4}{|l|}{$75-84$ years } \\
\hline No to moderate ill-health & $2.3 \%$ & $2.3 \%$ & $2.1 \%$ \\
\hline Severe ill-health & $14.2 \%$ & $17.8 \%$ & $20.5 \%$ \\
\hline All & $4.9 \%$ & $5.3 \%$ & $5.4 \%$ \\
\hline
\end{tabular}

\section{5- years}

\begin{tabular}{|l|l|l|l|}
\hline No to moderate ill-health & $14.0 \%$ & $12.8 \%$ & $11.3 \%$ \\
\hline Severe ill-health & $40.1 \%$ & $42.5 \%$ & $44.9 \%$ \\
\hline All & $24.9 \%$ & $23.8 \%$ & $22.1 \%$ \\
\hline
\end{tabular}

All age groups

No to moderate ill-health Severe ill-health

\begin{tabular}{|l|l|l|}
\hline $2.4 \%$ & $2.4 \%$ & $2.1 \%$ \\
\hline $19.2 \%$ & $22.3 \%$ & $24.1 \%$ \\
\hline
\end{tabular}

\begin{tabular}{|c|c|c|c|}
\hline All & $5.6 \%$ & $5.8 \%$ & $5.4 \%$ \\
\hline \multicolumn{4}{|l|}{ Total LTC } \\
\hline \multicolumn{4}{|l|}{$65-74$ years } \\
\hline No to moderate ill-health & $2.6 \%$ & $2.2 \%$ & $2.6 \%$ \\
\hline Severe ill-health & $15.0 \%$ & $14.6 \%$ & $16.4 \%$ \\
\hline All & $3.9 \%$ & $3.4 \%$ & $3.4 \%$ \\
\hline \multicolumn{4}{|l|}{$75-84$ years } \\
\hline No to moderate ill-health & $12.6 \%$ & $12.0 \%$ & $11.7 \%$ \\
\hline Severe ill-health & $34.3 \%$ & $37.1 \%$ & $42.1 \%$ \\
\hline All & $17.3 \%$ & $16.4 \%$ & $17.2 \%$ \\
\hline \multicolumn{4}{|l|}{ 85- years } \\
\hline No to moderate ill-health & $19.7 \%$ & $18.4 \%$ & $16.8 \%$ \\
\hline Severe ill-health & $75.0 \%$ & $75.9 \%$ & $81.7 \%$ \\
\hline All & $59.3 \%$ & $55.3 \%$ & $54.4 \%$ \\
\hline \multicolumn{4}{|l|}{ All age groups } \\
\hline No to moderate ill-health & $10.6 \%$ & $10.0 \%$ & $9.6 \%$ \\
\hline Severe ill-health & $41.2 \%$ & $43.1 \%$ & $46.3 \%$ \\
\hline All & $16.4 \%$ & $15.7 \%$ & $15.1 \%$ \\
\hline
\end{tabular}

Table 4: Proportion of people in the population receiving LTC by age and level of ill-health, Sweden, 2000-2010.

These data show that older people in Sweden who reported severe ill-health were three times more likely than older people who reported good health or only mild ill-health to receive public home-based LTC services. As in Japan there was a strong age-gradient, but this mainly affected those with severe ill-health. For those reporting no ill-health or only moderate ill-health the proportion receiving home-based LTC services was highest in the group aged 74-85 years. Only small differences could be seen over time-for the total population there was a slight decrease as the proportion with severe ill-health among older people declined.

Around 5\% of older people in Sweden were recorded as living in institutional care. This figure has been stable over the last ten years. As expected there was a strong connection between the level of ill-health experienced and this form of LTC provision. As is the case in Japan only a very small proportion of Swedish people aged 65-74 years lived in institutional care, but in the age group 85 years and above around one in four older people lived in such accommodation. Older people suffering severe ill-health were also much more likely to be living in institutional care (45\%) than younger people reporting a similar level of ill-health (8\%).

In Sweden almost half of the people 65 years and older reporting severe ill-health received public LTC and this proportion was increasing. The proportion among those with no or only moderate illhealth was much lower-around $10 \%$-and decreasing. In total the proportion receiving LTC in Sweden decreased reflecting a positive development in health status. As in Japan a much higher proportion of 
those aged 85 years and above than of the younger old received LTC services even after taking account of health differences.

\section{Discussion}

The analyses show many similarities but also many differences between the two countries. It seems that the Japanese LTC system, which was introduced in 2000 , has not yet fully matured. Before the year 2000 LTC services mainly consisted of provision of care in hospital and the local government LTC services only covered older adults with limited financial resources who lived alone. Most elderly were taken care of by their relatives. Public services tended to be seen as welfare support and consequently they had a stigma attached to them.

The revised scheme with its system of premium payments and copayments by recipients means that people now feel that they are purchasing their own LTC services. This change in perception resulted in a rapid increase in LTC service provision in the period 2000-2005. Similar developments took place in Sweden but happened much earlier-in the 1970s and the 1980s. By 1985 the system was fully developed and an accepted part of welfare service provision.

The reform that took place in Japan in 2006 was aimed at limiting the increasing cost of LTC service provision. There has been a slowdown in the provision of services but it is not clear if this is a result of the reform or simply that the system has now matured and the provision has stabilized after the initial increases. In comparison in Sweden with its more long-standing LTC system there has been very little change in level of provision in the period 2000-2010. However, major changes had already taken place during the 1990s when Sweden faced a severe economic crisis. The cost development will be further discussed in a future article.

Changing demographics mean that in both countries there has been a rapid increase in the number of old adults. In Japan the most rapid increase has been among the very old where numbers have nearly doubled in ten years. In Sweden there has also been a substantial increase in the number of very old people, but the increase has not been as fast as in Japan. By way of comparison-in Japan the proportion of persons 65 years and above doubled between 1970 and 1995, while in Sweden the same increase took 100 years. In recent years the most rapid increase in Sweden has been among the younger old reflecting the large number of baby-boomers who are reaching old age, i.e. people born in the early 1940s. In Japan the baby-boomers were born 1947-1949 and will reach old age somewhat later than their Swedish counterparts.

In both countries population surveys show a decrease in dependency/ill-health in the age groups 65-84 years at about the same rates. In Japan, however, there are indications of increased dependency among the oldest, whereas in Sweden it is the opposite. There the most rapid improvement is found among the very old. There is of course considerable uncertainty involved in these population estimates but the general pattern should be valid. The distribution of LTC services between the two categories of need-for Japan "dependent" and "no or slight dependency", for Sweden "severe" or "no to moderate ill-health"differs between Japan and Sweden. The reason is that the two measures of need for LTC are defined in a different way. "Dependent" is defined in terms of dependency for activities of daily life (ADL); "Severe illhealth" is measured by the Statistics Sweden Health index, which is a composite measure with no explicit reference to ADL (cf above). This means that you may need help in the activities in daily life without having severe ill-health and vice versa. As a consequence LTC is provided for many persons in Sweden with no or only moderate illhealth as measured by the health index. Dependency in ADL, defined as for Japan, is more closely related to need for LTC and vice versa and it follows that in Japan fewer persons with no or slight dependency receive LTC and a very high proportion of those with dependency receive LTC. Regardless of the dependency measure used there is a much higher proportion of the older people with dependency or illhealth who receive LTC services than among those without. However, it should be noted that in Japan the difference becomes smaller for the very old. This mainly affects home-based services and reflects the fact that very old people may need help in their daily life even if they are not ADL-dependent-especially those who live alone. The total proportion of very old people that receive LTC is very similar in Japan and Sweden (50\% and 54\% respectively.).

Prevalence rates for institutional care in Sweden are twice those of Japan. Here of course there is a clear difference depending on the level of dependency/ill-health. Also in both countries the proportion of individuals in institutional LTC increases rapidly with age-regardless of dependency/ill-health level. It should be noted in this context that the rate of institutional care is dependent on the availability of institutional places. In Japan the development of institutional places has been severely limited and as a consequence many older adults are waiting to be admitted to institutions.

In both countries the proportion of people receiving LTC increases with age. In Sweden this increase goes irrespective of level of ill-health, whereas in Japan it is mostly seen by the non ADL-dependent, since nearly all ADL-dependent persons receive LTC regardless of age (which may be an exaggeration, cf above).

The calculations presented above are based on two different types of data sources-dependency and ill-health data obtained through Japanese and Swedish population surveys, and LTC data obtained from the Japanese LTCI system in nine municipalities and in Sweden from special municipal surveys carried out in eight municipalities. National estimates are then achieved by "blowing up", i.e. calibrate proportionally, the sample-based or local data-based results to national level.

There are obviously many different problems involved in these calculations. Firstly, the survey used to estimate dependency must be large enough, representative and unbiased. We judge NUJLSOA meets these criteria but there are limitations. Secondly, the local data on provision in relation to needs must be nationally representative. In this case, however, it is possible to calibrate to agreement with national provision data assuming that relative levels in relation to age-group and dependency are the same. The question of the national representativeness of the municipalities has been discussed in previous articles $[10,11]$.

Further on, survey and municipality data have to be harmonized in order to achieve valid estimates of the proportion of individuals in the population who receive LTC services. For obvious reasons the two data sources used in the Japanese case are not fully compatible. However, both NUJLSOA and the municipal LTC data contain a lot of variables on functional limitations related to the need for LTC services, which makes it fairly easy to choose a common dataset to be used to define needs. The variables chosen were the standard variables used to define dependency in activities of daily living (bathing, dressing, using the toilet, transferring, feeding) [16]. However, as mentioned above there are indications that the proportion of ADL-dependent people receiving 
LTC services is exaggerated because dependency prevalence has been under-estimated. Also it cannot of course be fully ascertained whether or not the prevalence of disability in the nine municipalities included in the study is the same as in the rest of Japan.

The same type of problems affects the Swedish case. Here ADLdependency was judged to be unreliable because of low prevalence rates and missing observations. Therefore a composite index was used instead - the SCB ill-health index. This made it possible to harmonise the Swedish population and municipal data but at the expense of reduced comparability with the Japanese results, since different measures of LTC needs were use. However, the internal consistency was judged to be more important.

\section{Conclusions and Policy Recommendations}

Relating provision of LTC services to needs is very important for the public LTC policy-both in order to make a valid judgment of present developments and to assess the need of resources tomorrow. For analyses of the type shown here you cannot rely on official statistics covering the whole country. There simple does not exist national figures relating provision of LTC services to needs-in Japan or Sweden or in any other country. Thus you are forced to use special surveys based upon samples or provision in local areas. Using needs related data from special surveys and "blowing up" reliable municipal data to the national level is a way of relating the provision of national resources to national needs. The result is not perfect but gives important insights concerning the adequacy and the development of the LTC system.

What has been shown by the comparative analysis is that the LTC trends in Japan and Sweden are similar but with a time lag. In the last 10-15 years Japan has gone through a phase that Sweden lived through 25-30 years ago. This means that Japan now has reached a phase where some austerity is needed to achieve a sustainable development. Health promotion and disability prevention could somewhat alleviate that situation. Both countries are facing rapid increase in the number of old dependent persons. It is inevitable that this means having to increase the resources going to eldercare. Using these resources as efficient as possible becomes paramount. Improved knowledge through research on disability trends and the allocation of LTC services is important in order to maintain the welfare ambitions both countries share.

\section{Acknowledgements}

Statistics Sweden (Statistiska centralbyrån, SCB) of the Swedish government funded SSLC data collection. The Swedish Ministry of Health and Social Affairs funded the study's analysis through the Swedish National Study on Aging and Care (Regeringsbeslut (government decision 1999-11-11 and onwards). Japanese funding by
JSPS KAKENHI Grant number 23330184. The authors declare that there is no conflict of interest.

\section{References}

1. Campbell J, Ikegami N (2000) Long-term insurance comes to Japan. Health Affair 19: 26-39.

2. Kurube N (2014) Assessment Instrument and Allocation of Services in Japan, Eldercare policies in Japan and Scandinavia-Aging societies east and west. Palgrave MacMillan, New York.

3. Tsutsui T (2001) Public Long-Term Care Insurance System in Japan. An Overview and a Care Needs Certification Scheme, OECD Report/2001, What \& How, is our Japanese LTC Insurance systems working? - Coming up with novel design of LTC Insurance and Care-Needs Certification Program. Iryo-Bunkasha.

4. Lagergren M (2002) The systems of care for frail elderly persons: The case of Sweden. Aging Clin Exp Res 14: 252-257.

5. Trydegard GB, Thorslund M (2010) One uniform welfare state or a multitude of welfare municipalities? The evolution of local variation in Swedish eldercare. Social Policy and Administration 44: 495-511.

6. Woittiez I, van Gameren E, Pommer E (2007) International comparisons of long term care use: A micro-analysis of differences between countries. IHEA 2007 6th World Congress, Explorations in health economics paper.

7. Boyd M, Bowman C, Broad JB, Connolly MJ (2012) International comparison of long-term care resident dependency across four countries (1998-2009): A descriptive study. Australas J Ageing 31: 233-240.

8. Lagergren M, Kurube N, Parker M (2009) A comparison of Long-term Care Recipients in Japan and Sweden. Hallym International Journal of Aging 11: 119-133.

9. Lagergren M, Kurube N, Parker M (2010) Provision of Long-term Care in Relation to Needs - a comparison of Japan and Sweden. Hallym Int J Aging 12: 63 -78.

10. Lagergren M, Kurube N (2014) Provision of Long-term Care in Relation to Needs in urban and rural municipalities in Japan and Sweden. Geriatr Gerontol Int 14: 315-327.

11. Lagergren M, Kurube N (2014) Comparing long-term care recipients in urban and rural municipalities in Japan and Sweden. J Aging Soc Pol 26: $1-14$.

12. Karlsson M, Mayhew L, Plumb R, Rickayzen B (2004) An international comparison of long-term care arrangements. Cass Business School, City University, London, UK.

13. Shimizutani S (2013) The future of long-term care in Japan. RIETI Discussion Paper Series 13-E-064.

14. Mitchell O, Piggott J, Shimizutani S (2004) Aged-care support in Japan: Perspectives and challenges. NBER (National Bureau of Economic Research) Paper Series. Cambridge, MA, USA.

15. Yong V, Saito Y (2012) Are there education differentials in disability and mortality transitions and active life expectancy among Japanese older adults. Findings from a 10-year prospective cohort study. J Gerontol BPsychol 67: 343-353.

16. Katz S, Ford AB, Moskowitz RW, Jackson BA, Jaffe MW (1963) Studies of illness in the aged. JAMA 185: 914-919. 